\title{
Comparison of anteroposterior lip positions of the most preferred facial profiles of the Nepalese people
}

\author{
Dr. Manish Bajracharya', Dr. Umesh Parajuli², Dr. Abhilasha Khanal ${ }^{3}$, Dr. Neesha Shrestha ${ }^{4}$, \\ Dr. Ujjwal Pyakurel ${ }^{5}$ \\ ${ }^{1}$ Associate Professor, ${ }^{3}$ Assistant Professor, ${ }^{4}$ Consultant Orthodontist \\ Orthodontic Unit, Dental Department, National Academy of Medical Sciences, Bir Hospital, Nepal \\ ${ }^{2}$ Associate Professor \\ Department of Orthodontics, College of Dental Surgery, Gandaki Medical College, Pokhara, Nepal \\ ${ }^{5}$ Assistant Professor \\ Department of Orthodontics, Kantipur Dental College, Kathmandu, Nepal \\ Corresponding author: Dr. Manish Bajracharya; Email: manishbajracharya@gmail.com
}

\section{ABSTRACT}

Introduction: Though cephalometric analysis of both hard and soft tissue has been done extensively for the treatment planning in orthodontics and orthognathic surgery in Nepalese people for years, they are all based on the norms for the Caucasians. No research has been done to establish the most favored profile amongst the Nepalese. The purpose of this study was to find out the most preferred well balanced or most favored facial profile from a series of 13 silhouettes with varying position of anteroposterior lip position by a group of Nepalese lay persons and general dental surgeons.

Materials and Methods: Average profile for male and female were constructed from the profile of 50 Nepalese males and females with normal occlusions and without history of orthodontic and prosthetic replacement. The lips were then protruded or retruded in 1-mm increments and a series of 13 silhouettes were constructed for each male and female with the average profile in the center. The silhouettes were then given to 500 dental surgeons and lay persons each and were asked to rank the 3 most preferred facial profiles in order of preferences.

Result: Both the general dental surgeons and the lay persons tend to prefer flatter profile than average for both the sexes. Both the groups preferred more flat profile for women compared to males. The least favored profile was the most protrusive one for both the groups.

Conclusion: This research shows that lay persons and the general dental surgeons preferred retruded profile than the average profile though prior research show that Nepalese people have an average profile convex.

KEYWORDS: Facial esthetics, Profile preferences, Nepalese population.

\section{INTRODUCTION}

Most patients undergo orthodontic treatment to enhance their beauty. The definition of beauty is difficult and has been tried by many artists and painters in the past. The ideal facial esthetic was considered to be of Aphrodite by the Greeks during the $4^{\text {th }}$ century BC. ${ }^{1} A$ flat or concave profile was representation of both male and female. Similarly, Leonardo had even tried to formulate a mathematical formula for defining the beautiful profile. He introduced a magical series also known as Fibonacci series or the "Golden Proportion". ${ }^{2}$ This number 0.1618 was used by Ricketts as a reference number for the beauty protocol.Edward Angle considered the Apollo as the most esthetic pleasing profile and treated patients on the basis. ${ }^{1}$

Treatment planning in orthodontics now a days, generally depends on the normal value of the given ethnic groups. Many analyses regarding the cephalometric values of well-balanced face have been done and generally the 
protocol for the orthodontic treatment has been based on these values. ${ }^{3-9}$ However, treating a patient with reference to normal cephalometric values may not be considered beauty in every case. ${ }^{10-12}$ The concept of beauty may change with time. What was considered beauty in the past may not be so appealing in the present. Besides, now days, individuals are generally exposed to different medias through televisions and internet which may influence the perception of beauty.

Nepalese dentists generally refer books that are based on Caucasian values and treat patients accordingly. However, the perception of the beauty of the layperson may be different from that of the normal values. In today's world of technology, everyone is exposed to different media such as the internet televisions and social medias.All these may affect the perception of pleasing profile. Therefore, profile considered pleasing by dental professional may not be pleasing for the lay person. So, this article aims to determine the perception of well balanced and pleasing profile amongst the Nepalese lay person and the dental professional. The purpose of this study was to determine the best and worst soft tissue anteroposterior lip position of a given series of well-balanced facial profile silhouettes of each sex amongst the Nepalese lay person and the dental professionals. Facial silhouettes were chosen in this study to avoid any subjective differences such as the hairline, eyes and the complexion of the skin.

\section{MATERIALS AND METHOD}

This was a hospital based prospective study conducted at Department of Orthodontics, National Academy of Medical science, Bir Hospital for a duration of one year from Aug 2020 to July 2021 after obtaining ethical clearance from institutional review committee National Academy of Medical science, Bir Hospital (ref no:705). Written consents were obtained from the volunteers who participated to have their lateral cephalogram radiographs taken. Average silhouette was obtained from 50 cephalometric analyses of 25 males and 25 females' subjects.

All the radiographs were taken by the same person for all the subjects. The including criteria were a normal occlusion with class I molar and canine relation, whole complement of teeth present except the third molars, no spacing, slight or no crowding, no congenital or traumatic defects, ANB angulation between 2 to 4 degrees and no previous orthodontic treatment and prosthetic replacement.

Cephalometric radiographs were taken with teeth in maximum intercuspation, and lips relaxed in Natural head position. The cephalostat used was Rotagraph plus model MR05. Focus film distance was 1.65 inch and focus patient distance were 1.5 meters or 59 inches. All the radiographs were taken with exposure maintained at $85 \mathrm{kVp}$ and current $10 \mathrm{~mA}$ with filtration of $2.5 \mathrm{~mm}$ of Al.eq. All the radiographs were traced with hand on acetate paper sheets and the measurements were obtained with the help of vernier caliper for linear measurements and protractor for angular measurements which recorded up to $0.02 \mathrm{~mm}$ and 0.5 degrees respectively. All these tracing was done by the same operator to avoid inter-examiner variability. Seven angular and 2 linear measurements were obtained for soft tissue analysis (Fig 1). The mean values and the standard deviation obtained from the soft tissue analysis for each sex are shown in table I.

For the purpose of testing the intra-examiner error, 20 cephalometric radiographs (10 from maleand 10 from female) were randomly selected and retraced after a month by the same operator. The tracings were analyzed by Dahlberg'sformula for any significant difference between the two tracings. The test showed that there was not any significant difference between the two measurements.

The average profile was prepared each for male and female. Then a series of 13 profiles were prepared for men and women with the average profile in the center. The lips were protruded or retruded in $1 \mathrm{~mm}$ from the average profile and the changes were done parallel to the Frankfurt Horizontal plane. Profile 1 was the most retrusive and profile 13 was most protrusive Fig 2.

The profile raters were 500 lay person ( 250 men with mean age of $29.2+7.6$ and 250 women with mean age of $30.6+6.7)$ and 500 dental professionals ( 210 males with mean age of $31.6 \mathrm{SD}+4.7$ and 290 females with mean age of $29.5+3.2$ years). None of the lay persons were employed in anydental hospital or dental clinics till the time of their enrollment in this study.All were asked to choose the best 3 profiles (1st being the best) and the worst 3 profiles ( $1 \mathrm{st}$ being the worst) from the series. Friedman test with pairwise comparison was done for all the variables within males and females best and worst profiles. Mann Whitney $U$ test was done to 
compare the selections between general dentist and lay person. All the statistical analysis was done using the software SPSS version 17.0. The level of significance was set at $\mathrm{P}<0.05$.

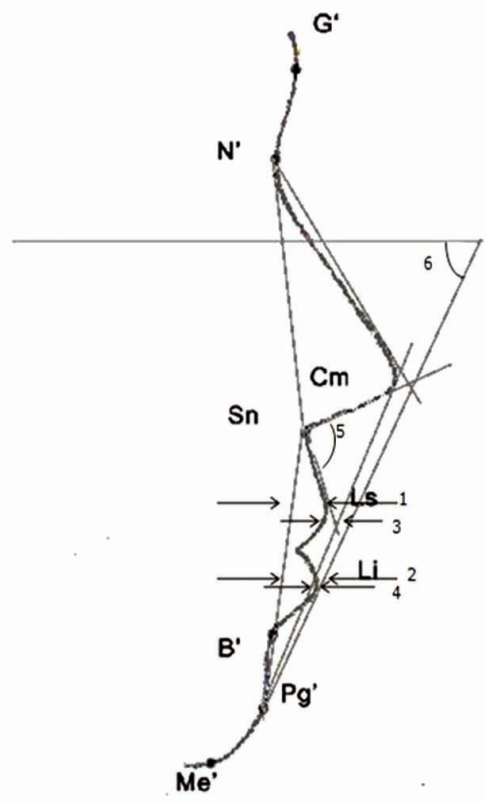

Fig 1.: Soft tissue cephalometric reference points and analysis: 1, upper lip protrusion (Ls to Sn-Pg'); 2, lower lip protrusion (Li to $\mathrm{Sn}-\mathrm{Pg}^{\prime}$ ); 3, upper lip to E-Line (Ls to E-line); 4, lower lip to E-line); 5, Nasolabial angle (Cm-SnLs); 6, Z-angle (chin/lip line to FH plane)
Table I: Mean and Standard deviation of the Nepalese population

\begin{tabular}{|c|c|c|c|c|}
\hline \multirow{2}{*}{ Variables } & \multicolumn{2}{|c|}{ Males $(n=50)$} & \multicolumn{2}{|c|}{ Females $(n=50)$} \\
\hline & Mean & SD & Mean & SD \\
\hline \multicolumn{5}{|l|}{ Facial form } \\
\hline $\begin{array}{l}\text { Angle of Nasal } \\
\text { convexity }\left(^{\circ}\right)\end{array}$ & 27.54 & 2.68 & 27.76 & 3.48 \\
\hline $\begin{array}{l}\text { Collumellar length } \\
\text { angle }\left({ }^{\circ}\right)\end{array}$ & 20.23 & 1.55 & 21.91 & 3.15 \\
\hline Nasal tip angle $\left(^{\circ}\right)$ & 83.27 & 4.99 & 84.55 & 6.11 \\
\hline $\begin{array}{l}\text { Facial convexity } \\
\left(\mathrm{G}^{\prime}-\mathrm{Sn}-\mathrm{Pg}^{\prime}\right)\left({ }^{\circ}\right)\end{array}$ & 14.88 & 2.11 & 13.91 & 3.30 \\
\hline \multicolumn{5}{|l|}{ Lip position } \\
\hline $\begin{array}{l}\text { Nasolabial angle } \\
\left(\mathrm{Cm}^{\prime}-\mathrm{Sn}-\mathrm{Ls}\right)\left({ }^{\circ}\right)\end{array}$ & 102.98 & 9.53 & 102.98 & 9.53 \\
\hline $\begin{array}{l}\text { Upper Lip } \\
\text { protrusion (Ls to } \\
\text { Sn-Pg') (mm) }\end{array}$ & 4.67 & 1.04 & 4.8 & 1.51 \\
\hline $\begin{array}{l}\text { Lower Lip protrusion } \\
\left.\text { (Li to } \mathrm{Sn}-\mathrm{Pg}^{\prime}\right)(\mathrm{mm})\end{array}$ & 3.58 & 1.18 & 4.04 & 1.16 \\
\hline $\begin{array}{l}\text { Inferior labial } \\
\text { sulcus angle }\left(^{\circ}\right)\end{array}$ & 114.22 & 7.41 & 113.59 & 7.11 \\
\hline
\end{tabular}

\section{Male}

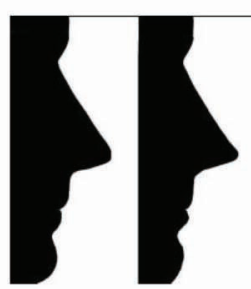

1

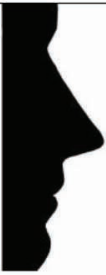

3

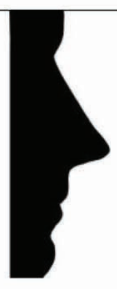

4

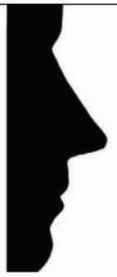

5

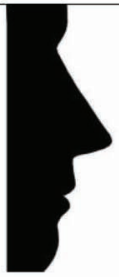

6

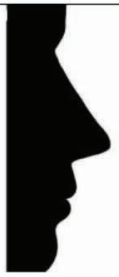

7

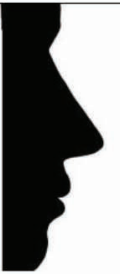

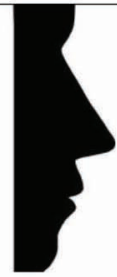

9

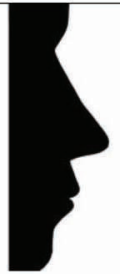

10

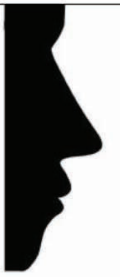

11

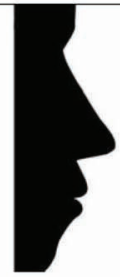

12

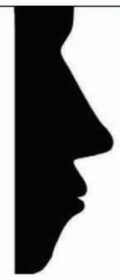

13

Female

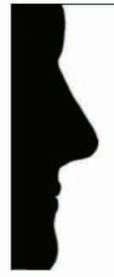

1

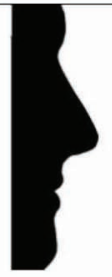

23

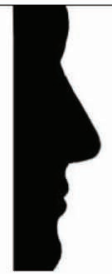

3

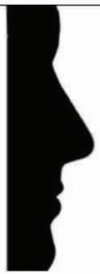

4

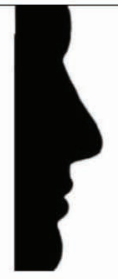

5

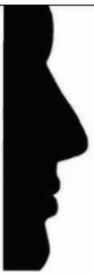

6

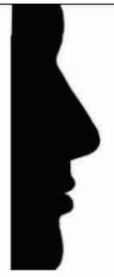

7

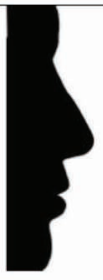

8

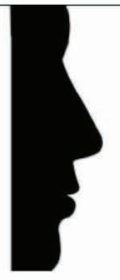

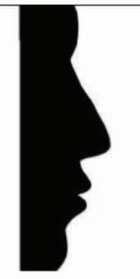

10

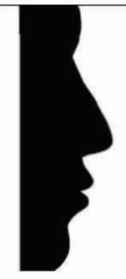

11

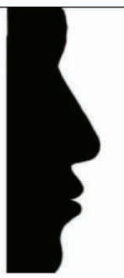

12

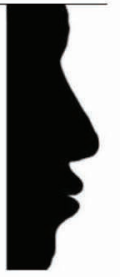

13

Fig: 2: Series of 13 silhouettes of men and women given for rating to lay persons and dental professionals 


\section{RESULTS}

The best three profiles as rated by general dentists were 5,6 and 7 for males (Figure 3) and 4, 5 and 6 for females (Figure 3 ) and there was a significant difference between the three selections for best as well as worst profiles (Table II and Table III). Similarly, the lay persons considered 7, 6 and 8 for men and 5, 6 and 7 for females as the best profiles (Figure 3). However, there was no significant difference between 1st Best and 2nd Best profiles for males (Table IV) and females (Table $\mathrm{V}$ ). For rest pairwise comparison, there was a significant difference for both males and female profiles selection. Both groups considered 13 as the worst profiles of all.
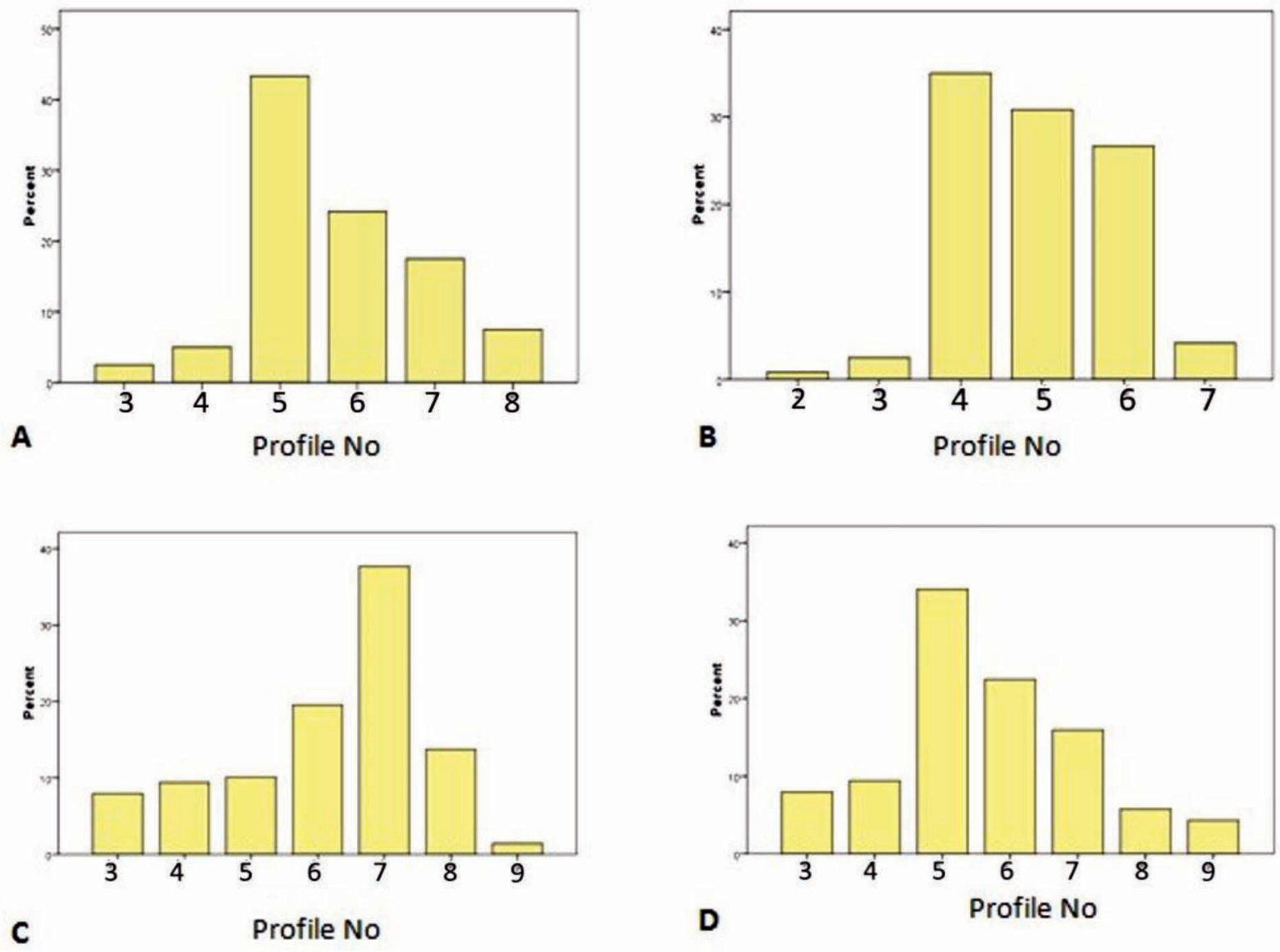

Figure 3: Rating of the profile by General Dentists and Lay person A: Male profile as rated by General dentist; B: Female profile as rated by General Dentist; C: Male profile as rated by lay person; D: Female profile as rated by lay person

When the rating for the best profiles for males and females were compared between the lay person and the dentists, it was seen that there was a significant difference between them except between the male profile 8 and 7 that is 3 rd Best profile and the worst profiles for the female (Table VI)

Table II: Best Male profile as judged by Dentist

\begin{tabular}{|l|l|l|l|l|}
\hline Sample1-Sample2 & Test statistics & Standard Error & Standard test statistics & P value \\
\hline MaleB1-MaleB2 & -0.276 & 0.063 & -4.364 & $<0.005$ \\
\hline MaleB1-MaleB3 & -0.840 & 0.063 & -13.282 & $<0.005$ \\
\hline MaleB2-MaleB3 & -0.564 & 0.063 & -8.918 & $<0.005$ \\
\hline
\end{tabular}

Friedman test with pairwise comparison 
Table III: Best female profile as judged by Dentist

\begin{tabular}{|l|l|l|l|l|}
\hline Sample1-Sample2 & Test statistics & Standard Error & Standard test statistics & P value \\
\hline FemaleB1-FemaleB2 & -0.430 & 0.063 & -6.799 & $<0.005$ \\
\hline FemaleB1-FemaleB3 & -0.902 & 0.063 & -14.262 & $<0.005$ \\
\hline FemaleB2-FemaleB3 & -0.472 & 0.063 & -7.463 & $<0.005$ \\
\hline
\end{tabular}

Friedman test with pairwise comparison

Table IV: Best male profile as judged by Lay person

\begin{tabular}{|l|l|l|l|l|}
\hline Sample1-Sample2 & Test statistics & Standard Error & Standard test statistics & P value \\
\hline MaleB1-MaleB2 & -0.024 & 0.063 & -0.379 & 0.704 \\
\hline MaleB1-MaleB3 & -0.300 & 0.063 & -4.743 & $<0.005$ \\
\hline MaleB2-MaleB3 & -0.276 & 0.063 & -4.364 & $<0.005$ \\
\hline
\end{tabular}

Friedman test with pairwise comparison

Table V: Best female profile as judged by Lay Person

\begin{tabular}{|l|l|l|l|l|}
\hline Sample1-Sample2 & Test statistics & Standard Error & Standard test statistics & P value \\
\hline FemaleB1-FemaleB2 & -0.094 & 0.063 & -1.486 & 0.412 \\
\hline FemaleB1-FemaleB3 & -0.782 & 0.063 & -12.365 & $<0.005$ \\
\hline FemaleB2-FemaleB3 & -0.688 & 0.063 & -10.878 & $<0.005$ \\
\hline
\end{tabular}

Friedman test with pairwise comparison

Table Vl: Comparison between Lay person and Dentist for males and females

\begin{tabular}{|l|l|l|l|l|}
\hline \multicolumn{2}{|c|}{ Group } & N & Mean Rank & P value \\
\hline MaleB1 & Dentist & 500 & 404.76 & $<0.005$ \\
\hline & Lay person & 500 & 596.24 & \\
\hline MaleB2 & Dentist & 500 & 445.43 & $<0.005$ \\
\hline & Lay person & 500 & 555.57 & \\
\hline MaleB3 & Dental & 500 & 472.25 & 0.072 \\
\hline & Lay person & 500 & 528.75 & \\
\hline FemaleB1 & Dentist & 500 & 430.96 & $<0.005$ \\
\hline & Lay person & 500 & 570.04 & \\
\hline FemalB2 & Dentist & 500 & 455.34 & $<0.005$ \\
\hline & Lay person & 500 & 545.66 & \\
\hline FemaleB3 & Dentist & 500 & 449.97 & \\
\hline & Lay person & 500 & 551.03 & \\
\hline
\end{tabular}




\begin{tabular}{|l|l|l|l|l|}
\hline \multicolumn{2}{|c|}{ Group } & N & Mean Rank & P value \\
\hline MaleW1 & Dentist & 500 & 522.97 & 0.001 \\
\hline & Lay person & 500 & 478.03 & \\
\hline MaleW2 & Dentist & 500 & 561.21 & $<0.005$ \\
\hline & Lay person & 500 & 439.79 & \\
\hline MaleW3 & Dentist & 500 & 541.69 & $<0.005$ \\
\hline & Lay person & 500 & 459.31 & \\
\hline FemalW1 & Dentist & 500 & 487.99 & 0.083 \\
\hline & Lay person & 500 & 513.01 & \\
\hline FemaleW2 & Dentist & 500 & 511.45 & 0.200 \\
\hline & Lay person & 500 & 489.55 & \\
\hline FemaleW3 & Dentist & 500 & 511.07 & 0.235 \\
\hline & Lay person & 500 & 489.93 & \\
\hline
\end{tabular}

\section{Mann Whitney U test}

For the most favored male profile chosen by the dentists, the values obtained for upper lip to $\mathrm{Sn}-\mathrm{Pg}^{\prime}$ is $2.53 \mathrm{~mm}$ and lower lip to $\mathrm{Sn}-\mathrm{Pg}^{\prime}$ is $1.33 \mathrm{~mm}$. The most favored lip protrusion relative to the esthetic line ranged from $-6.0 \mathrm{~mm}$ for upper lip and lower lip to E-line ranged from $-4.0 \mathrm{~mm}$.

For the most favored female profile as chosen by the general dentists, the values obtained for upper lip to Sn-Pg' was $1.86 \mathrm{~mm}$ and lower lip to $\mathrm{Sn}-\mathrm{Pg}^{\prime}$ was $1.06 \mathrm{~mm}$. The most favored lip protrusion relative to the esthetic line was $-6.0 \mathrm{~mm}$ for upper lip and lower lip to E-line was -2.0mm. (Table VII)

Similarly, from the most favored profile for male chosen by the lay person, the values obtained for upper lip to Sn-Pg' ranged from 3.53 to $5.53 \mathrm{~mm}$ and lower lip to $\mathrm{Sn}-\mathrm{Pg}^{\prime}$ ranged from 2.33 to $4.33 \mathrm{~mm}$. The most favored lip protrusion relative to the esthetic line ranged from -5.0 to $-7.0 \mathrm{~mm}$ for upper lip and lower lip to E-line ranged from -3.0 to $-5.0 \mathrm{~mm}$. (Table VIII)

For women, the most favored profile as chosen by lay person, the values obtained for upper lip to $\mathrm{Sn}-\mathrm{Pg}$ ' ranged from 2.86 to $4.86 \mathrm{~mm}$ and lower lip to $\mathrm{Sn}-\mathrm{Pg}^{\prime}$ ranged from 2.06 to $4.06 \mathrm{~mm}$. The most favored lip protrusion relative to the esthetic line ranged from -5.0 to $-7.0 \mathrm{~mm}$ for upper lip and lower lip to E-line ranged from -1.0 to $-3.0 \mathrm{~mm}$.

TableVII: Values for the best male and female profile as judged by dentists

\begin{tabular}{|l|l|l|}
\hline \multicolumn{1}{|c|}{ Variables } & \multicolumn{1}{c|}{ Males } & \multicolumn{1}{c|}{ Females } \\
\hline Lip position & 2.53 & 1.86 \\
\hline $\begin{array}{l}\text { Upper Lip protrusion } \\
\text { (Ls to Sn-Pg') (mm) }\end{array}$ & 1.33 & 1.06 \\
\hline $\begin{array}{l}\text { Lower Lip protrusion } \\
\text { (Li to Sn-Pg') (mm) }\end{array}$ & -6.0 & -6.0 \\
\hline $\begin{array}{l}\text { Upper Lip to E-Line } \\
\text { (Ls to E Line) (mm) }\end{array}$ & -4.0 & -2.0 \\
\hline $\begin{array}{l}\text { Lower Lip to E-Line } \\
\text { (Li to E Line) (mm) }\end{array}$ & \\
\hline
\end{tabular}

Table VIII: Values for the best male and female profiles as judged by the Lay Person

\begin{tabular}{|l|l|l|}
\hline \multirow{2}{*}{ Variables } & \multicolumn{2}{c|}{ Range } \\
\cline { 2 - 3 } & \multicolumn{1}{|c|}{ Males } & \multicolumn{1}{c|}{ Females } \\
\hline Lip position & & \\
\hline $\begin{array}{l}\text { Upper Lip protrusion } \\
\text { (Ls to Sn-Pg') (mm) }\end{array}$ & $3.53 \sim 5.53$ & $2.86 \sim 4.86$ \\
\hline $\begin{array}{l}\text { Lower Lip protrusion } \\
\text { (Li to Sn-Pg') (mm) }\end{array}$ & $2.33 \sim 4.33$ & $2.06 \sim 4.06$ \\
\hline $\begin{array}{l}\text { Upper Lip to E-Line } \\
\text { (Ls to E Line) }(\mathrm{mm})\end{array}$ & $-5.0 \sim 7.0$ & $-5.0 \sim 7.0$ \\
\hline $\begin{array}{l}\text { Lower Lip to E-Line } \\
\text { (Li to E Line) (mm) }\end{array}$ & $-3.0 \sim 5.0$ & $-1.0 \sim 3.0$ \\
\hline
\end{tabular}




\section{DISCUSSION}

The main objective of orthodontics is not only to obtain good occlusion and function but also good facial and dental esthetics. ${ }^{13}$ Physical appearance has been known to have a greater impact in an individual's social status. ${ }^{6,7}$ The criteria for patient's satisfaction are no doubt very complex and it may depend on many factors such as patient expectation, self-assessment and psychological condition present before and after treatment. One of the contributing factors in patient satisfaction involves subjective evaluation of facial esthetics. Any analysis based on cephalometrics, or facial "normative values" has one inherent weakness, and that is "beauty is not the norm" and the esthetic outcome is often the patient's main criterion for success. ${ }^{8}$

There have been several studies done in different ways in order to know the facial preferences., 10 Lucker et al has reported that in general, symmetric faces, straight profiles and facial proportions that are close to the population average are considered to be the most attractive. ${ }^{11}$ Esthetics and beauty may differ between racial groups and have been reported in many previous studies. ${ }^{14-17}$

In this study we decided to rate silhouettes instead of the photographs in order to avoid any subjective bias like the skin complexion, hair style and eyes. ${ }^{17}$ Most of the orthodontic treatments in Nepal are done as per the norms of the Caucasians which are found to be orthognathic than the norms of the Nepalese population. Research have shown that lips are responsive to the alteration of the tooth position and therefore critical in orthodontic diagnosis and treatment planning than other parts of the face like nose and chin which can only be altered with orthognathic surgery. ${ }^{18}$ So, this study was done in order to find out the preferred anteroposterior lip position amongst the lay person and the dentists practicing in Nepal.

According to our result, we found that the most preferred profile as perceived by the general dentist in order were 5,6 and 7 as the best three profiles whereas for females, the best three profiles in orders were 4, 5 and 6. When pairwise comparison was done, it was found that there is a significant difference in the selection among dentist while choosing for both male and female best profiles. So, the tendency was to choose a more retrusive anteroposterior lip position relative to the average profile was seen amongst the general dentists. When judged by the lay person, they preferred the average profile as the best for males i.e., profile 7 .
Profile no 6 and 8 were considered as the second and third best. Similarly, they preferred orthognathic profile i.e., profile 5 as the best for the females followed by profile no 6 and 7 respectively. Both the dentist and the lay person considered protrusive profile as the worst. Pairwise comparison was done to see if any difference were present in the selection by the lay person. It was seen that there was no any significant difference between the first and second best profiles for both males and females. It seems that the lay person are not keen enough to differentiate the profiles that were close enough. The reason may be the dentist have well trained eyes to differentiate minor differences in profile. The difference between the lay person and the general dentist regarding the anteroposterior lip position should be taken into consideration in determining the well-balanced facial profile. Similar studies done in the Japanese population reported that flatter profile was preferred. ${ }^{13,14,15}$ In their research it was reported that both the orthodontics and the dental students tend to prefer a flatter profile than the average silhouette which is similar to the result obtained in our study. ${ }^{14}$ Similarly, it was reported that the Koreans and Japanese adults prefer a retruded profile, even though their profiles have historically been characterized by more convex facial features. The tendency to prefer more retruded lips was more evident for the women. In our study too, even though the facial profile preferred was flatter than the average profile for both male and females, the preferred female profile was flatter in comparison to the males. This is however in contradiction to a common perception in the western countries where more protrusive lips are more desirable in women than men. ${ }^{5}$ Our study also contradicts with the study done by Jen Soh et al. in which it was seen that bimaxillary protrusion was better received in Chinese female profiles than in Chinese male profiles. ${ }^{16}$ The participants in the study however preferred the normal and bimaxillary retrusive profiles as the most attractive. Similar study in Turkish population showed that they preferred orthognathic profile in both sexes. ${ }^{19}$ Second to it, fuller and protrusive lips in females were more admired where as retrusive lips in males were preferred. This finding also is in contradiction with our study. Another study reported that raters tend to prefer a more retruded lip position as the facial convexity decreases and a slightly more protruded lip position compared with chin protrusion cases as the facial convexity increases. ${ }^{12}$ In our study, the worst profile was the most protrusive profile, and this result is similar to other studies carried out in 
different racial groups. ${ }^{14,15}$ Depending on our study we derived the values that were preferred by the general dentist and the lay person for the facial profile.

The orthodontics textbooks for the Bachelor of Dental Surgery in this part of the world are generally of Europeans and Americans authors. During study, the students refer to the norms of the Caucasians. Most of the treatments are also based on the Caucasian norms till date. This may be one of the factors that may lead the general dentists to prefer flatter profile than the lay persons even though the average profile of the Nepalese population has been found to be more convex than the Caucasians. Though this study was done within a confined population of lay person and dentists, the authors hope that this study can be a gateway to further investigate the facial preferences so that the treatments are delivered as per patient centered rather than doctor centered.

\section{CONCLUSIONS}

1. Both the dentists and lay person preferred retruded lip position for women than the average silhouette.

2. For male, the dentists preferred retruded lip positions than the average silhouette whereas the lay persons preferred average profile.

3. This result show that the general dentist and the lay person in Nepal preferred flatter profile for women compared to males which is in contradiction to the western world.

\section{Acknowledgments:}

The authors would like to sincerely thank Associate Professor Dr. Rajesh Gyawali and Assistant Professor Dr. Jamal Giri, College of Dental Surgery; B. P. Koirala Institute of Health Sciences, Dharan for their significant guide in preparing this article.

\section{OJN}

\section{REFERENCES}

1. Peck S, Peck L. Selected aspects of the art and science of facial esthetics. Semin Orthod 1995;1(2):105-26.

2. Swami V, Furnham A. The psychology of physical attraction. London ; New York: Routledge; 2008.

3. Rakhshan V, Ghorbanyjavadpour F. Correction to: Anteroposterior and vertical soft tissue cephalometric norms of Iranians, interethnic comparisons, sex dimorphism, and the effect of age on cephalometric variables. Oral Maxillofac Surg 2019;23(2):263.

4. Gulati R, Jain S. Cephalometric norms for orthognathic surgery for North India (Eastern Uttar Pradesh). Natl J Maxillofac Surg 2011;2(1):33-7.

5. Hamdan AM, Rock WP. Cephalometric norms in an Arabic population. J Orthod 2001;28(4):297-300.

6. Huang WJ, Taylor RW, Dasanayake AP. Determining cephalometric norms for Caucasians and African Americans in Birmingham. Angle Orthod 1998;68(6):503-11; discussion 12.

7. Jain P, Kalra JP. Soft tissue cephalometric norms for a North Indian population group using Legan and Burstone analysis. Int $\mathrm{J}$ Oral Maxillofac Surg 2011;40(3):255-9.

8. Moate SJ, Darendeliler MA. Cephalometric norms for the Chinese: a compilation of existing data. Aust Orthod J 2002;18(1):19-26.

9. Wu J, Hagg U, Rabie AB. Chinese norms of McNamara's cephalometric analysis. Angle Orthod 2007;77(1):12-20.

10. Bronfman CN, Janson G, Pinzan A, Rocha TL. Cephalometric norms and esthetic profile preference for the Japanese: a systematic review. Dental Press J Orthod 2015;20(6):43-51.

11. Zarif Najafi $\mathrm{H}$, Sabouri SA, Ebrahimi E, Torkan S. Esthetic evaluation of lip position in silhouette with respect to profile divergence. Am $\mathrm{J}$ Orthod Dentofacial Orthop 2016;149(6):863-70.

12. Oliveira MD, Silveira BL, Mattos CT, Marquezan M. Facial profile esthetic preferences: perception in two Brazilian states. Dental Press $J$ Orthod 2015;20(3):88-95.

13. Mantzikos T. Esthetic soft tissue profile preferences among the Japanese population. Am J Orthod Dentofacial Orthop 1998;114(1):1-7.

14. Foster E. Profile preferences among diversified groups. Angle Orthod 1973;43(1):34-40.

15. Czarnecki ST, Nanda RS, Currier GF. Perceptions of a balanced facial profile. Am J Orthod Dentofacial Orthop 1993;104(2):180-7.

16. Ioi H, Nakata S, Nakasima A, Counts AL. Anteroposterior lip positions of the most-favored Japanese facial profiles. Am J Orthod Dentofacial Orthop 2005;128(2):206-11.

17. Shimomura T, loi H, Nakata S, Counts AL. Evaluation of well-balanced lip position by Japanese orthodontic patients. Am J Orthod Dentofacial Orthop 2011;139(4):e291-7.

18. El Asmar R, Akl R, Ghoubril J, El Khoury E. Evaluation of the ideal position of the maxillary incisor relative to upper lip thickness. Am $\mathrm{J}$ Orthod Dentofacial Orthop 2020;158(2):264-72.

19. Celebi AA, Tan E, Gelgor IE, Colak T, Ayyildiz E. Comparison of soft tissue cephalometric norms between Turkish and European-American adults. ScientificWorldJournal 2013;2013:806203. 